\title{
On Interaction between Technological Innovation and Core Competitiveness of Enterprise
}

\author{
Huiyan LI \\ Management Department, Sanya University, Hainan 572000, P.R. China
}

Hao WANG

Sanya Aviation \& Tourism College, School of Tourism \& Hotel Management, Hainan 572000, P.R. China

\begin{abstract}
With the speed of China's economic development, technological innovation becomes fundamental motive of enterprise forward development. The core competitiveness is important way for enterprise to maintain long-term development advantage and secure economic benefits. The enterprise technology innovation is direct source of core competitiveness, so the enterprise technological innovation is particularly important to the long-term survival and development of enterprise. The analysis explored the relationship between technology innovation and enterprise core competitiveness based on the theory of enterprise technology innovation and core competitiveness.
\end{abstract}

KEYWORD: Enterprise; Technology innovation; Core competitiveness; Relationship

\section{GENERAL INSTRUCTIONS}

Technological innovation means combination of new technologies and products and applied to the production and sales of new products in the sectors and ultimately generates economic and social benefits of a range of commercial activity through innovative technical concept, developing by the company technical staff. The purpose of enterprise technological innovation is to achieve a breakthrough in technology and innovation as a model is not the use of a particular technology to change the status of enterprises completely.[1] This innovation has a high commercial value and potential to help companies expand into new markets, accounting for more resources to enable enterprises to achieve higher economic returns. The core of technology innovation is to make a combination of factors of production used in the actual production, so that commercial production systems can reap excessive profits and beat other competitors in the market, to maintain long-term competitive advantage and survival status. Therefore, the technical innovation goal is to adapt to the market development and get economic benefits, social benefits and technological development, this usually help businesses gain an advantage core competitiveness.

\section{OVERVIEW OF CORE COMPETITIVENESS OF ENTERPRISES}

Enterprises can occupy the market initiative and process advantage in the market through the core competitiveness, the core competitiveness of enterprises reflects the comprehensive capabilities, it is a collection of enterprise systems in various organizations capabilities such as absorption capacity, development and integration capabilities expand capacity, etc.

Absorptive capacity means capture and learning ability of various advanced technologies and information.[2] Development and integration capabilities are good at integrating the various technologies and information to a unique competitive in a particular area strength which the rival unsurpassed. Expand ability is to deeply use the integrated core competitiveness to develop the core products and extend to multiple market segments.

From the perspective of resource acquisition point of view, the core competitiveness can help companies take a lot of market resources in the market and maintain long-term competitive advantage. it is necessary for enterprise to understand the rational development and utilization of resources in the allocation of limited resources and operation, achieving enterprises sustainable development through the rational allocation and ultimately reap excessive profits. Therefore, enterprises need to enhance the production capacity to compete in the market, but also need to strengthen 
strategic capability access to resources, these are the main factors constitute the core competitiveness of enterprises.

From the perspective of competency point of view, core competitiveness of enterprises is a comprehensive reflection of corporate coordination of technical, management, and organizational abilities, containing combination of theory and practical in different sectors and levels. Competency-based perspective emphasize that management capabilities, resource allocation capabilities, the ability to build knowledge, technology development capabilities and research capabilities are the part of core competitiveness. One enterprise which has the capacity for sustainable development must possess above ability and effective use in the market and gain experience, ultimately constitute the company's own competitive advantage, continuous access to excess profits and develop the potential market.

\section{THE PROMOTION OF TECHNOLOGICAL INNOVATION TO THE CORE COMPETITIVENESS}

\subsection{Technology innovation allows companies have sustainable competitive advantage}

With the increasingly fierce competition in the international market, the enterprise must establish a unique competitive advantage and take the road of sustainable development to get the chance of survival and development in competitive environment.[3] Through technological innovation, enterprises build the core competitiveness, and by keeping the core competitiveness, enterprise improve the competitiveness, help to occupy a strong position in the market and obtain more market resources, creating huge economic benefits. From the point of view of long-term development, the enterprise needs the core competitiveness to maintain a dominant position, while the source of power of the core competitiveness is technological innovation. Thus, enterprise need to rely on technological innovation to drive business forward, technological innovation is the fundamental way for enterprises to long-term survival and development.

\subsection{Technological innovation is key factor for enterprises survival}

Innovation is the determining factor for competitive advantage and essential condition for promoting things forward. With the accelerated pace of change in our market economy, enterprises should follow the law of development and characteristics of the market, scientific and reasonable adjustments selfdevelopment strategies. Technological innovation is the key factor in business survival and the effective protection for core competitiveness cultivation. Technological innovation must to be reasonable choice and modest investment within the capacity to minimize risk. If the enterprise loses the technological innovation, it will lose its core competitiveness.

\subsection{Technology innovation helps enterprises to reduce costs and enlarge earnings}

When the ultimate goal of technological innovation is to improve the quality and competitiveness of their products, making enterprises stay in market dominance through technological innovation. Technological innovation is re-integration process of enterprise existing resources, production conditions, organizational structure and management conducted, which aims to establish an efficient production management system and achieve the objective of maximizing corporate profits. Through technology innovation, enterprise can develops diversification and open up new markets resources to help businesses obtain long-term competitive advantage and economic benefits. Any part of the value chain are likely to possess the company's core capabilities which exist in the production, research and development, support value-added and other aspects, that is, each link of the enterprise value chain belongs to the field of technological innovation. To increase investment in technological innovation, use lower cost of investment exchange for higher economic returns, maintain long-term competitive advantage of enterprises, these are the important way to cultivate the core competitiveness of enterprises.

\section{THE IMPACT OF CORE COMPETITIVENESS TO ENTERPRISE TECHNOLOGICAL INNOVATION}

\subsection{Core competencies allow technological innovation with new impetus}

Cultivation of core competitiveness is the basis of enterprise long-term survival. Cultivation enterprise core competitiveness can "wake up" potential technological innovation capability. In the market competition, competitors will quickly imitate and learn new techniques and gradually disintegrate and erode the current market share, the core competitiveness of enterprises will be threatened, a new round of core competencies needed impetus of the rise of technology innovation. [4] The core competencies can help businesses grow, also allow technological innovation competencies to be released and stimulate enterprise technological innovation. 


\subsection{Core competencies allow enterprise maintain and consolidate overall strength}

The core competence is evolving long-term development of enterprise, it is a unique competitive advantage and business model which enterprises build. The decrease of enterprise core competitiveness will make enterprise fall into a deadlock that cannot be moving forward and bring incalculable loss. Through analysis of core competitiveness and market situation, enterprise needs concentrate all resources to cultivate their core competitiveness. In order to maintain long-term competitive advantage and meet the requirements of market development, enterprise needs to constantly strengthen technical innovation investment and improve the technological innovation capability, enhancing the intrinsic strength.

\subsection{Enterprise core competitiveness can strengthen coordination and stability within the organization management system}

By enhancing the core competitiveness, the ability to work with various departments within the enterprise and between staff gradually strengthened and become more effective in solving the problems.[5] The maturity of the organization and management system help companies carry out technological innovation better and form the overall advantages to enhance the probability of success and reduce risk. Companies need to make each employee has a profound understanding of the core competencies contents and carry out regular evaluation meeting to maintain the balanced development of enterprise's core competitiveness.

\subsection{The core competitiveness drive technology re- innovation}

First, when the core competitiveness threatened in the market competition, companies need to choose new technological innovation in order to enhance their competitive advantage. Improvement of enterprise R \& D capabilities performance in the enterprise growing research capacity, technology development capability to meet the changing of customer needs.

Second, look for new growth point of core competitiveness and foster the point to the enterprise core competitiveness. Identify the product leading competitive advantage by business management, technology, marketing, market segments. Introduction advanced technology talent and cooperate with universities, research institutions, individual researchers based on these growth point to foster enterprise core competitiveness.
Finally, through interactive between core competitiveness and technological innovation, the enterprise can create internal corporate culture and values. Corporate culture is the inherent quality and feature of the enterprise, the values is the common understanding of the staff and the organization. Through interactive development in enterprise's core competitiveness and technological innovation, the enterprise can stimulate sense of responsibility and creativity inspiration, improve the efficiency of work, and establish the correct organizational values and personal values to enhance the soft power. By shaping the internal corporate culture, the enterprise can create the right organizational and employee values, this also is key sector in consolidate and innovative enterprise core competitiveness.

\section{SUMMARY}

Core competence is the key factor which affects enterprise long-term survival and development. The source for enterprise core competitiveness is technological innovation; the core competitiveness still reacts to technological innovation and can drive enterprises to new peak. In increasingly market competitive environment, the enterprises possess core competencies and maintain long-term and sustainable development through technological innovation is an important research topic in current. The core competitiveness of enterprises makes them possess market resources and gain market share, building a reasonable business development model. Technological innovation promote the core competitiveness going forward, the enterprise need to actively improve management methods and mechanisms to grasp the interaction between core competitiveness and technological innovation. This enables enterprise success in the fierce market competition and sustainable development.

\section{REFERENCES}

[1] B B Tyler. The complementarity of cooperative and technological competencies: are source-based perspective. J Eng Tech-Manage, 2010, 18(1): 1-27.

[2] C. K. Prahalad \& Gray Hamel. Cooperate and its core competitive force, Journal of marketing, 2008(6):32-34.

[3] John P Workman. Engineering's interactions with marketing group in an engineering-driven organization. IEEET transactions on Engineering Management, 1995, 42(2): 1037-1046.

[4] Tidd, J Bessant. Managing innovation: integrating technological, market and organizational change. John Wiley \& Sons Ltd, 2000: 139-145.

[5] Anneke, Cohen P.M. Working wisdom: timeless skills and vanguard strategies for leanring organizations. San Francisco: Jossey-Bass. 1995: 147-154. 